\title{
Editorial
}

\section{Social Determinants of Health and its Role in Headache Disorders}

\author{
Mario Fernando Prieto Peres ${ }^{1,2}$ (D) , Marcelo Moraes Valença ${ }^{3}$ (D), Juliana Ramos de Andrade ${ }^{3}$ (D), \\ Erlene Roberta Ribeiro dos Santos ${ }^{4}$ (D)
}

\author{
${ }^{1}$ Instituto de Psiquiatria, Hospital das Clinicas HCFMUSP, Faculdade de Medicina, Universidade de São Paulo, São Paulo, Brasil \\ ${ }^{2}$ Hospital Israelita Albert Einstein, São Paulo, Brasil \\ 3Universidade Federal de Pernambuco, Pernambuco, Brasil \\ ${ }^{4}$ Universidade Federal de Pernambuco, Centro Acadêmico de Vitória, Vitória de Santo Antão, Pernambuco, Brasil
}

\section{$\bigotimes$}

Mario F. P. Peres. MD, PhD mario.peres@hc.fm.usp.br Instituto de Psiquiatria, Hos pital das Clinicas HCFMUSP, Faculdade de Medicina, Universidade de São Paulo, São Paulo, Brazil
Understanding the health-disease dynamic changes over time is imperative to plan future strategies in the processes involved in the development of society.' Currently, the model for explaining this process is based on the expanded concept of health, which, based on morbidity and mortality gradients, understands the influence of the conditions in which people are born, grow, live and age, which are defined as social determinants of health (SDH). Factors such as economic stability (employment, income, expenses, debt, medical bills, support), habitability, biological, territory, neighborhood and physical environment (housing, transportation, safety, parks, playgrounds, walkability, zip code/geography), education (literacy, language, early childhood education, vocational training, higher education), food security (hunger, access to healthy options), community and social context (social integration, support systems, community engagement, discrimination, stress), access to health care system (health coverage, provider availability, provider linguistic and cultural competency, quality of care) are the major determinants. ${ }^{2,3,4}$ Social determinants of health are connected to health disparities, being a significant target of the World Health Organization's health policy as they result in mortality, morbidity, life expectancy, health expenses, health status and functional limitations. ${ }^{2}$

Many initiatives are available to address the social determinants of health, focusing on both health and non-health sectors (e.g., schools, workplaces, religious temples, community areas). ${ }^{3}$ Promoting health equity is a key factor in public policies, considering that life and work conditions of the population are closely linked to social and cultural factors as well as psychological, emotional and health conditions, which influence the occurrence of disease and mortality. Therefore, promotion, prevention, cure and rehabilitation are primary measures based on health education and guidelines of universal health systems. ${ }^{4}$

Even though migraine is considered one of the top contributors to the burden of disease, responsible for the high direct and indirect costs to a society, it is underrecognized, underdiagnosed and undertreated. Limited information is available regarding the role of SDH in migraine or headache disorders in general. Low socioeconomic status, ethnicity, education, food insecurity and childhood experiences have been attributed to affect migraine in the general population. ${ }^{5}$ Hammond and Stinchcombe found SDH relationships in migraine for both women and men in the Canadian adult population, where social status, belonging to a minority group, and physical activity were the highlighted aspects. ${ }^{6}$ It is essential to highlight gaps in the structure of health services and the continuing education process for professionals in the area, who often do not use the international 
classification of headaches ${ }^{7}$ as a reference to classify case data and direct towards clinical management.

This is a call for more studies on the topic; a better understanding of modifiable health aspects related to headache disorders will help guide public policies to improve the management and resource allocation for headache sufferers.

\section{References}

1. Santos ISF, Arruda LES, Silva LR and Santos ERR. Understanding the health-disease process and the birth of Social Medicine. Jornal Memorial da Medicina 2020;2(2):8-14 Doi: 10.37085/jmmv2.n2.2020.pp.814

2. World Health Organization (WHO). Health 2020: A European Policy Framework and Strategy for the 21st Century. Copenhagen, Denmark: World Health Organization, Regional Office for Europe; 2013.
3. Rosendale N. Social Determinants of Health in Neurology. Neurologic Clinics 2022;40(1):231-247 Doi: 10.1016/j.ncl.2021.08.012

4. Sigerist HE. Health. In HE Sigerist. Medicine and human welfare. Yale University Press. Reproduced in Journal of Public Health 1996;17(2).

5. Befus DR, Irby MB, Coeytaux RR and Penzien DB. A Critical Exploration of Migraine as a Health Disparity: the Imperative of an Equity-Oriented, Intersectional Approach. Current Pain and Headache Report 2018;22(12):79 Doi: 10.1007/s11916-018-0731-3

6. Hammond NG, Stinchcombe A. Health Behaviors and Social Determinants of Migraine in a Canadian Population-Based Sample of Adults Aged 45-85 Years: Findings From the CLSA. Headache 2019;59(9):15471564 Doi: 10.1111/head.13610

7. Headache Classification Committee of the International Headache Society (IHS) The International Classification of Headache Disorders, 3rd edition. Cephalalgia 2018:38(1):1-211 Doi: 10.1177/0333102417738202 